\title{
The End of Modern Civilization: How Death Can Lead Us Home
}

Rae K. Mitchell, York University

Modern civilization is inherently unsustainable, and is thus implicated in the

progressive annihilation of the natural world. This annihilation is necessary in a system that is perpetuated through capitalist notions of economic productivity in which the importation of goods is required. As each landbase is only capable of sustaining the life forms that exist within its ecosystem, importation means the death of particular 'other' bodies and life forms. The only possible endpoint for a system which depends on the importation of finite resources to support itself is death, and for the first time in history, the possibility of an end to all of life on earth is scientifically verifiable (Bahrenberg \& Dutkowski, 1993, p. 286).

Thus, the majority of humans live within urban systems that contain the seed of their own destruction, if not the destruction of all other life forms upon which they interdepend. This infrastructure is enabled through a neoliberal imperium (Agathangelou and Ling, 2002, p. 2) which requires both continual, pre-emptive deaths and the fear of death. A starting point for change requires the adoption of an ethics of life. Buddhist understandings of the human condition and ecoregionalism, a model for community living grounded in such a morality, provide a framework for understanding and action that recognizes the inter-dependence of living beings while facing the inevitability and power of death. Through this model, acknowledging death becomes a societal practice, one that may be key to the continuance of life.

Modern industrial society is characterized by its fear of death. In The Order of Things, Michel Foucault (2001) argues that, "Homo economicus is not the human being who represents his own needs to himself, and the objects capable of satisfying them; he is the human being who spends, wears out, and wastes his life in evading the imminence of 
death" (p. 280). The liberal ideal is eternal life - immortality secured through the cooptation of land, at the expense of the beings who live within the natural systems that operate within that land. This creation of property is the central act that in turn allows for the accumulation of goods and money, which are the physical substances capable of existing beyond the death of the individual. In this way modern industrial society partitions the natural world into exclusive fragments which in turn feed the need for the permanence and control that death seems to threaten, by providing a base of materiality that is expected to outlast the mortality of the human accumulator. Thus, fear of death is supplanted by the need to control the material world -- and society's proxy "science, which has as its ultimate (and proximate) goal the conversion of the wild and wildly unpredictable natural world into something orderly, predictable, and controllable" (Jensen, 2006, p. 161) is one of the means that this control is realized. This is reflected in the hope that technology will resolve the ecological crises that are part and parcel of modern industrial societies (i.e. that science can be the means for remaining unaccountable for the consequences of capitalism).

The regulation of bodies through technology is another way that science is used in the service of sustaining modern industrial society. As Ferenc Fehér and Agnes Heller explain in their text Biopolitics (1994), "Modern manufacturing industry, which has often been one-sidedly (sic) identified with modernity as such, has been based from the beginning on the notion (or rather on the negative utopia) that the machine will not only check and overrule human labour but will eventually replace it completely" (p. 14) completing the almost total alienation from productive activity (such as the procurement of food, water, and shelter) that links individuals with the source of their subsistence. As Fehér and Heller (1994) explain: "the systematic deterioration and crippling of the Body in industrial work is a constant feature of modern technology" (p. 14). In this way the "God of 
production," is "deeply devoted to the conversion of the living to the dead" (Jensen, 2006, p. 160).

An extension of bodies as productive machines, is the regulation of bodies as consumers. In modern society money becomes the means through which survival stuffs are secured, so that the individual is oriented to corporations and the state as the source of life, instead of the earth. This is the way that the modern nation-state has created what Anna M. Agathangelou and L.H.M. Ling (2009) refer to as "consumer citizenship" (p. 141). This consumerism develops the "hungry ghost" aspect within us, a being in Buddhist cosmology who "has a tiny mouth, the size of the eye of a needle, a thin neck and throat, skinny arms and legs and a gigantic belly. His mouth and neck are too small to let enough food pass through them to fill his immense belly, so he is always hungry" (Trungpa, 2002, p. 36). This aspect is cultivated in modern industrial society so that "we were periodically bent on catering solely to the needs of the continually unsatisfied sensuous, and subsequently, in an alternative fit we would try to raise ourselves to the level of the spirit and leave the corporeal completely behind" (Fehér \& Heller, 1994, p. 9). Such ascetic responses demonstrate how consumerism has literally forced the self contained by individual bodies to attempt an escape of the body, alienating it not only from the natural world, but also from its most direct link to nature - the body itself.

Consumerist and technological regulation of bodies, the keystones of modern civilization and the 'civilizing process,' reduce bodies to economically productive vessels. As Fehér and Heller (1994) explain: "an apparently self-contradictory trend underlies the 'civilizing process': it is tantamount to frantic efforts made in order to transform the human habitat into a genuinely 'humanistic' one by purging every trace of the physical existence of humans from it" (p. 16). This human element is the unique, individual, emissary of the 
natural world that is purged. Indeed, "the 'lost element' is the sense of the uniqueness of the corporeal existence (including the uniqueness of each individual), the capacity of grasping the wonder of the body which exists only once and which defies generalized norms and scientific explanations" (Fehér \& Heller, 1994, p. 18). In these ways we are made exnature, ex-land, and through the loss of and change in our relationship to the natural world, and even to our own bodies, made into ex-humans (Biehl, 2005, p. 317).

This is accomplished through the attempted elimination of all life, human and nonhuman alike - the (un)natural result of unchecked consumerism. Indeed, the very promise of modernity is "the complete mastery of nature" (Fehér \& Heller, 1994, p. 1) in addition to the "liberation of the Body" (Fehér \& Heller, 1994, p. 8). However, unique to this time in history is that, "not only do we still have the same old difficulties as had our ancestors with repressing, silencing and sublimating the 'nature in us,' but in addition we face an ecological crisis outside” (Fehér \& Heller, 1994, p. 1).

Through these processes, not all bodies are equal. This is true of both the 'Other,' that body which is most productive for the elite of the Global North to maintain in the periphery, with the most minimized access possible to recourse and autonomy, and of select nonhuman bodies, perhaps the most killable bodies of all. Judith Butler explores the meaning of this exclusion and violence by asking:

How then can one think through the matter of bodies as a kind of materialization governed by regulatory norms in order to ascertain the workings of heterosexual hegemony in the formation of what qualifies as a viable body? How does that materialization of the norm in bodily formation produce a domain of abjected bodies, a field of deformation, which, in failing to qualify as the fully human, 
fortifies those regulatory norms? What challenge does that excluded and abjected realm produce to a symbolic hegemony that might force a radical rearticulation of what qualifies as bodies that matter, ways of living that count as 'life,' lives worth protecting, lives worth saving, lives worth grieving? (Butler, 1999, p. 243)

Thus, the continual destruction of wild life through the pollution of food sources, water, and land, the mass elimination of wild spaces such as old growth forests, the drying up of rivers through the construction of dams, the enslavement of animals in industrial agriculture all depends upon the exclusion of animals in relation to the model body of the human (which itself is subjected to safety from or membership in the abjected realm of bodies that do not matter).

I suggest that the possibility for averting this kind of a death lies in the adoption of an ethics of life that is grounded in the natural world. In Endgame: The Problem of Civilization (2006) Jensen proposes an ethics that starts, literally, from the ground up. His starting point is the inalienable goodness of copious amounts of fresh, clean water (p. 31). For him, the foundation of morality has to acknowledge first and foremost, "I am an animal who requires habitat" (Jensen, 2006, p. 32). He goes on to explain:

If I understand that as human animals we require healthy landbases for not only physical but also emotional health, how will I perceive the morality of mass extinction? How does the understanding that humans and salmon thrived here in Tu'nes for at least twelve thousand years affect my perception of the morality of the existence of dams, deforestation, or anything else that destroys this long-term symbiosis by destroying salmon? (p. 32) 
This natural symbiosis is the basis for the notion of interdependence in Buddhist thought, which is the conception of, "reality as a dynamic interaction of mutually conditioning events, (that) posits no prime cause or unconditioned absolute to which occurrences can be traced in a linear fashion" (Macy, 1992, p. 18). This concept is mirrored in an understanding of bodies as fluid and co-created entities. What Judith Butler proposes in "Bodies That Matter" (1999), "is a return to the notion of matter, not as site or surface, but as a process of materialization that stabilizes over time to produce the effect of boundary, fixity, and surface we call matter" (Butler, 1999, p. 239). This interdependence and co-arising of phenomenon challenges the notion of a fixed "I" which exists separate from the world, and thus separate from others. This is the state that Agathangelou and Ling refer to as a "multi-and trans-subjectivity" (Agathangelou \& Ling, 2009, p. 130), the "('I in you and you in me') where selves and others reverberate with one another to construct a mutual subjectivity" (Agathangelou \& Ling, 2009, p. 130). This inter-being of all things connotes a responsibility to others, as "our mutual embeddedness makes us mutually accountable" (Agathangelou \& Ling, 2009, p. 86). Thus, an ethics that acknowledges our place within natural systems, as an animal with physical and emotional needs that are shared with others and which are experienced and obtained only in the context of relationship with others, creates the conditions for a life that is sustainable and moral.

Ecoregionalism is a model that puts these ethics into practice. In "An Ecoregional Strategy Towards a Fault-Tolerant Human-Environment Relationship," authors Gerhard Bahrenberg and Marek Dutkowski propose a strategy of ecoregionalism that manifests the principles of worldism, meaning it "shifts attention away from essentialized, reified structures that produce a unified, socio-political world order, state structures, and collective 
subjectivities...Worldism reorients our attention to the multiplicity of social ontologies at play and their power politics" (Agathangelou \& Ling, 2009, p. 125). Ecoregionalism helps in the movement towards the "multiplicity of social ontologies" by transferring the decision-making for a given locality to those who live there. Given that the ecological destructiveness of modern civilization lies in its importation of resources from the landbases of others, ecoregionalism attempts to "keep human intervention in the natural environment within the limits of its buffering capacity" (Bahrenberg \& Dutkowski, 1993, p. 289) by mapping out the areas required for communities of people to have "enough natural resources to become self-sufficient, which is a pre-requisite for autonomy" (Bahrenberg \& Dutkowski, 1993, p. 290).

In order for this mapping to not in and of itself form another type of violence it is essential to allow the people (and even the land, the animals and the plants) that live within a community to play a role in the determination of these boundaries, so that "only those people can participate in decision-making processes who live in the territory where the problem to be solved is located," thus, "competence is founded - among other things - on the territorial membership of people" (Bahrenberg \& Dutkowski, 1993, p. 292). In addition this model calls for the development of autonomous households, which provide a selfsupply of food to its members, thus increasing self-sufficiency and relieving the burden on industrial agriculture to provide foodstuffs (Bahrenberg \& Dutkowski, 1993, p. 293).

These are only a few possibilities that exist using ecoregionalism as a frame to contemplate next steps. What is powerful about this re-localization of decision-making and sufficiency is the way that it embodies many aspects of an ethics of life: it reaffirms the community's interdependence with the natural world by bringing the resources necessary for life into the proximity of home; it places responsibility for decision-making on those 
who will directly benefit or experience the consequences of those decisions, thus

facilitating growth, learning and responsibility, and it acknowledges that the human animal requires a habitat that is life fulfilling.

Civilization is sustained through the fear of death, which is really to say that it is sustained through the fear of bodies and natural systems, all of which operate according to cycles and influences that are outside the jurisdiction of economic control and therefore threaten the existence of the eternal, rational, property-owning individual upon which modern industrial society depends.

It is no accident that the endgame for this type of is not only its own obliteration, but the obliteration of the entire world, the violent, avoidable ecological collapse that faces us now: a mega-death that brings about the very thing that capitalist society has been constructed to deny.

Thus, this fear of death is creating the very conditions for the death that is feared. Averting the death of ourselves, if not all other creatures and life forms, requires an acceptance of death, and through that, the adoptation of an ethics of life that is grounded in the natural world. Ecoregionalism is a model that puts these concepts into practice. This transformation will not be easy, but it is essential and needs to be practical. As Trungpa explains,

Treading the spiritual path is painful. It is a constant unmasking, peeling off of layer after layer of masks. It involves insult after insult. Such a series of disappointments inspires us to give up ambition. We fall down and down and down, until we touch the ground, until we relate with the basic sanity of earth... When we are grounded, 
there is no room for dreaming or frivolous impulse, so our practice at last becomes workable. (Trungpa, 2002, p. 6)

The possibilities of transformation explored throughout this paper mean more then mere survival - they are key to the realization of a kind of dignity that our overdetermined participation in the destruction of our world denies us. In fact, the end of this civilization, as we have understood it so far, may be the very thing required to bring us home: to ourselves and to each other. 


\section{References}

Agathangelou, Anna M., \& L.H.M. Ling. (2009). Transforming world politics: From empire to multiple worlds. New York, NY: Routledge.

Bahrenberg, Gerhard, \& Dutkowski, Marek. (1993). “An Ecoregional strategy towards a fault-tolerant human-environment relationship.” In Dieter Steiner \& Markus Nauser (Eds.), Human ecology: Fragments of anti-fragmentary views of the world. New York, NY: Routledge.

Biehl, João. (2005). Vita: Life in a zone of social abandonment. Berkeley, CA: University of California Press.

Fehér, Ferenc, \& Heller, Agnes. (1994). Biopolitics. Brookfield, WI: Avebury.

Foucault, Michel. (2001). The order of things: An archaeology of the human sciences. New York, NY: Routledge.

Jensen, Derrick. (2006). Endgame: The problem of civilization. Toronto, ON: Steven Stories Press.

Macy, Joanna. (1992). Mutual causality in Buddhism and general systems theory. Albany, NY: State University of New York Press. 
Macy, Joanna. (1991). World as lover, world as self. Berkley, CA: Parallax Press.

Smith, Joseph Wayne, Positano, Sandro, Stocks, Nigel, \& Shearman, David. (2008). A New way of thinking about our climate crises: The rational-comprehensive approach. Queenston, ON: The Edwin Mellen Press.

Trungpa, Chogyam. (2002). The myth of freedom. Boston, MT: Shambhala.

Butler, Judith. (1999). “Bodies that matter.” In Janet Price \& Margrit Shildrik (Eds.) Feminist theory and the body: A reader. New York, NY: Routledge. 